\title{
Mid-ureteric obstruction due to diaphragmatic valve: Case report with review of literature
}

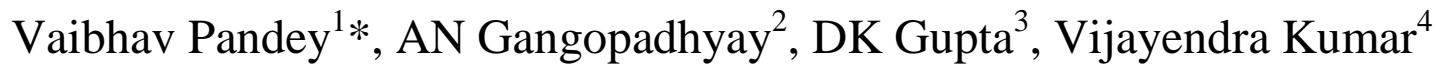 \\ ${ }^{I}$ M.B.B.S, M.S, M.Ch., Senior Resident, Department of Paediatric Surgery, Institute of Medical Sciences, \\ Banaras Hindu University, Varanasi, U.P. \\ ${ }^{2}$ M.B.B.S, M.S, M.Ch., Professor Department of Paediatric surgery, Institute of Medical Sciences, Banaras \\ Hindu University, Varanasi, U.P. \\ ${ }^{3}$ M.B.B.S, M.S, M.Ch., Professor Department of Paediatric surgery, Institute of Medical Sciences, Banaras \\ Hindu University, Varanasi, U.P. \\ ${ }^{4}$ M.B.B.S, M.S., Associate Professor Department of Paediatric surgery, Institute of Medical Sciences, Banaras \\ Hindu University, Varanasi, U.P.
}

\begin{abstract}
Congenital ureteric obstruction caused by a ureteric valve is an extremely rare entity. Our patient, a 6-year-old male, had undergone evaluation for recurrent pain in the left lower part of abdomen and was diagnosed as a case of left hydrouretronehrosis on ultrasound abdomen. Intravenous urography revealed left hydronephrosis and hydroureter with a cut-off in mid-ureteric region. Micturating cysto-urethrogram (MCUG) and cystoscopy were normal. Laparotomy with excision of valve with end to end uretro-uretrostomy was performed. Histopathology revealed Type II ureteric valve. A high index of suspicion is required to make a correct preoperative diagnosis.
\end{abstract}

Keywords: Ureteric stricture, ureteric valve, hydrouretronehrosis

\section{Introduction}

Congenital ureteric valves are extremely rare. Children with this disorder are often misdiagnosed as having either primary megaureter or ureterovesical junction obstruction. We report a case of mid- ureteric congenital valve with a review of the literature.

\section{Case report}

A 6-year-old male child presented with recurrent abdominal pain in the left lower part of abdomen. A renal ultrasound revealed left hydrouretronehrosis. The right kidney was normal. Intravenous urogram showed left hydronephrosis and hydroureter upto upper two-thirds of the ureter with a cut-off at junction of upper two third and lower one third [Fig 1]. MCUG and cystoscopy were normal. Renal scan showed a normally functioning left kidney with split renal function of $28 \%$ and an obstructive pattern. Patient was taken for laparotomy. Intraoperatively there was dilatation of ureter upto upper two third with narrowing distally. Stay sutures were taken at 3 and 9 o'clock position, and ureter was opened between the stays [Fig 2, 3]. There was a diaphragm with a central hole. Excision of ureteric segment with end to end uretro-uretrostomy was done with vicryl 6-0. Pathological examination revealed Type II ureteric valve lined by transitional epithelium overlying a stroma containing smooth muscle fibers and fibrous tissue. Patient had uneventful recovery. On one-year follow-up renal scan, there is $47 \%$ split renal function of left kidney without obstructive pattern.

\section{Discussion}

Congenital ureteric valves are a rare cause of ureteric obstruction. Only about 65 cases of ureteric valves have been reported since Wolfler described his first case in 1877 [1]. Rabinowitz et al classified ureteric valves as Type I or Type II, with Type I having smooth muscle present within the leaflet and Type II having smooth muscle at the base only. Morphologically ureteric valves can be classified on the basis of type of valves as cusp-like (leaflet), diaphragmatic or annular type [2]. Our case is a diaphragmatic Type II true ureteric valve, as demonstrated by histopathology.

Usually the presentation is with recurrent pain abdomen, fever or incidentally diagnosed hydrouretronephrosis [2]. Diagnosis of 'ureteric valves' in a patient presenting with hydrouretronehrosis can be met if following there is proven presence of transverse folds of the ureteric mucosa containing bundles of smooth muscle fiber on histological examination,, signs of obstructive disease above the valve with a normal ureter below it, and no other evidence of mechanical or functional obstruction [3].

Most commonly valves are reported in the upper ureter (50\%), followed by distal ureter (33\%) and least commonly in the mid-ureter (17\%). One case of multiple valves on the same side has also been described [1]. Bilateral involvement is exceedingly rare [1,2]. 
Various theories of embryogenesis of ureteric valves have been put forward. Two major theories which presently exist are the persistence of Chwalle's membrane and second is abnormal differential growth of ureteric bud with respect to metanephric blastema [2,4]. The persistence of Chwalle's membrane might explain the presence of lower ureteric valves but abnormal growth of ureteric bud seems more compatible with valves in upper and mid-ureter and also multiple valves in one ureter [2,4]. Diaphragmatic ureteral valves are a very rare cause of ureteric obstruction can be explained by improper recanalization or insufficient vascular supply [5]. Further valves can be due to iatrogenic injury [6]. The most common presentation of this condition includes flank pain, gross hematuria and urinary infection or can be detected incidentally while evaluating suspected cases of megaureters, ureteropelvic or ureterovesical junction obstruction [5]. More than 50\% of cases with ureteric valves also have associated urinary anomalies, including ureteric duplication, reflux, ectopic ureter, and contralateral hypoplastic kidney or renal agenesis [3]. Our patient had no associated complaints. Ureteric valve causing significant obstruction can be surgically excised with primary uretero-ureteral anastomosis [7]. Various minimal invasive techniques have been described including holmium laser ablation or removal of the valve with biopsy pens without resection [8]

\section{Conclusion:}

Despite the availability of advanced diagnostic radiological modalities, a high index of suspicion is needed to make the diagnosis of ureteric valve as a cause of unilateral hydronephrosis and hydroureter.

\section{Legends:}

Fig 1 Intravenous urography showing mid-ureteric obstruction

Fig 2 Mid-ureteric region showing site of web

Fig 3 Ureter divided showing web

\section{References:}

[1]. Daher P, Riachy E, Mourani C, Smayra T, Haddad S. An unusual case of bilateral primitive obstructed megaureters due to ureteric valves presenting with anuria at the age of 1 month. J Pediatr Surg. 2007;42:17-20.

[2]. Rabinowitz R, Kingston TE, Wesselhoeft C, Caldamone AA. Ureteric valves in children. Urology. 1998;51:7-11

[3]. Wall B, Wachter E. Congenital ureteric valve: Its role as a primary obstructive lesion: Classification of the literature and report of an authentic case. J Urol. 1952;68:684-90.

[4]. Maizels M, Stephens FD. Valves of the ureter as a cause of primary obstruction of the ureter: Anatomic, embryologic and clinical aspects. J Urol. 1980;123:742-7.

[5]. Docimo SG, Lebowitz RL, Retik AB, et al. Congenital midureteric obstruction. Urol Radiol. 1989;11:156-60.

[6]. Kilciler M, Erdemir F, Bedir S, et al. Ureteral membranous band causing uereteral obstruction after the ureterolithotomy. Int Urol Nephrol. 2006;38:467-8

[7]. Manzoni C. Urethral valves. Rays. 2002;27:87-8.

[8]. Aslam MZ, Gowda BDR Holmium laser ablation: a successful treatment option for an obstructing ureteric valve Can Urol Assoc J. Feb 2010; 4(1): E15-E16.

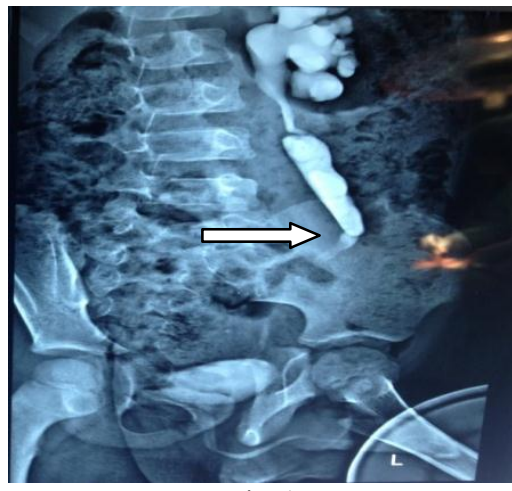

Fig 1

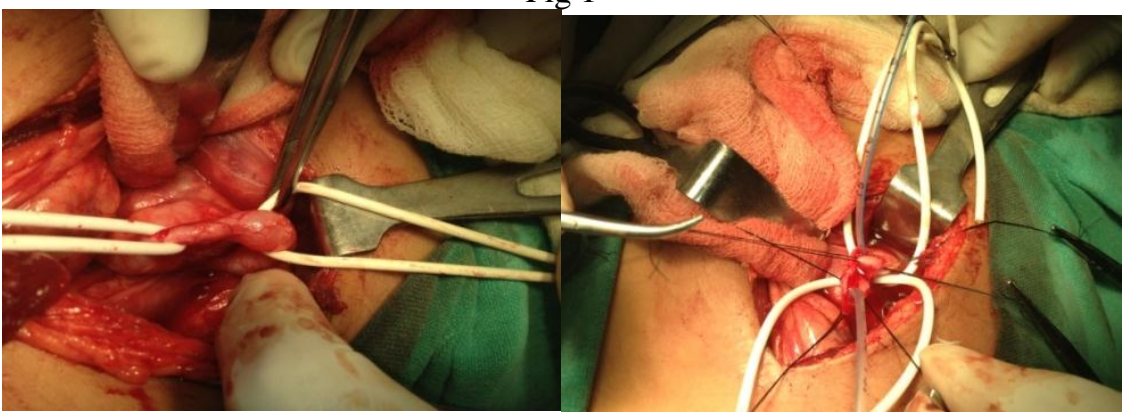

Fig 2

Fig 3 